\title{
Pharmacokinetic Concentration Test Code
}

National Cancer Institute

\section{Source}

National Cancer Institute. Pharmacokinetic Concentration Test Code. NCI Thesaurus. Code C87973.

A character or string that represents the short code name of the pharmacokinetic concentration assessment. 